Acta Crystallographica Section B

Structural

Science

ISSN 0108-7681

Editor: Carolyn P. Brock

\title{
The structure of $\mathbf{G a}_{4} \mathbf{T i}_{21} \mathbf{O}_{48}$
}

\section{J. Lloyd, I. E. Grey and L. A. Bursill}

This electronic document was scanned from an archival copy of material deposited to accompany a paper published in an IUCr journal. In many cases the only accessible copy was a microfilm of a poor-quality original. 


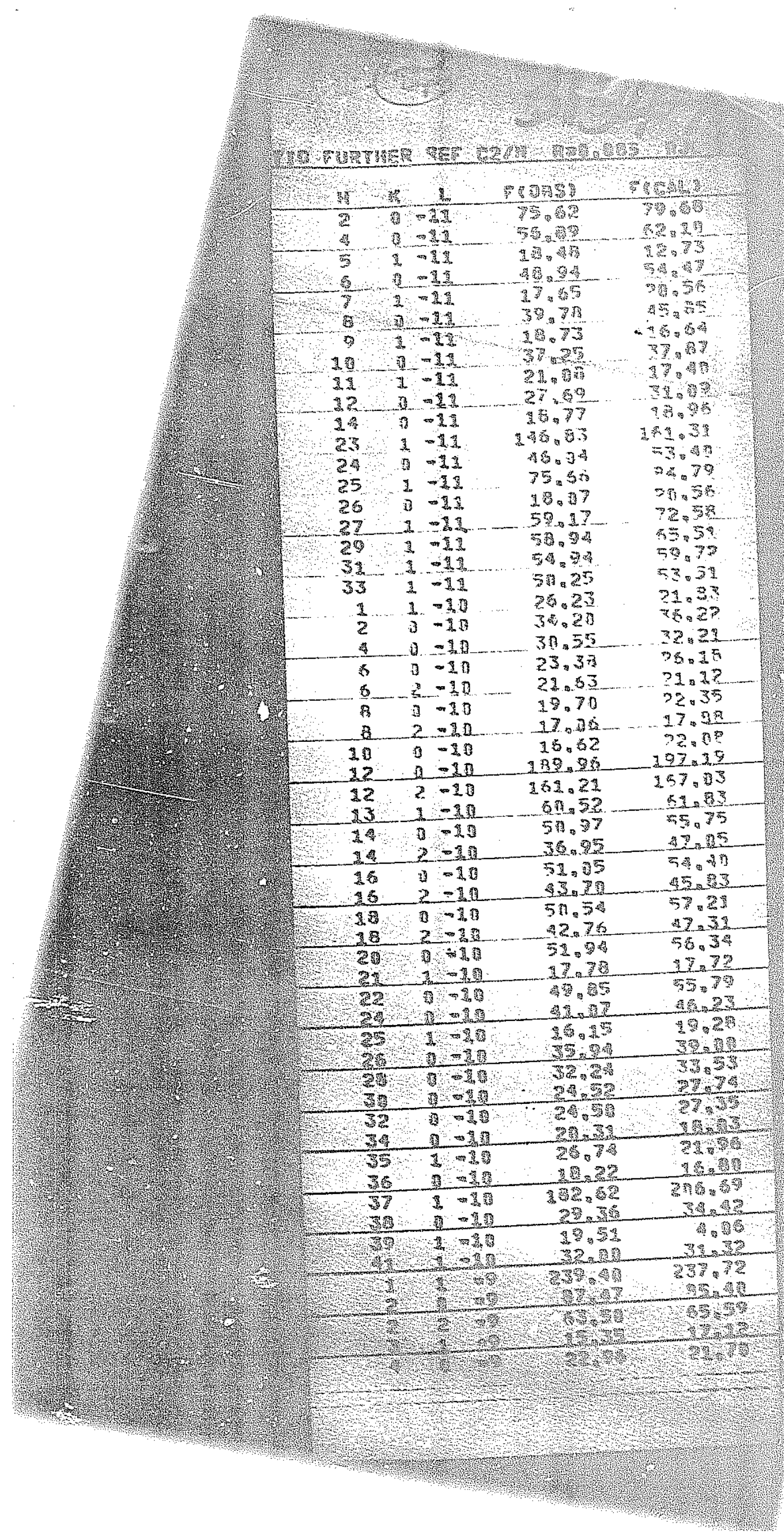




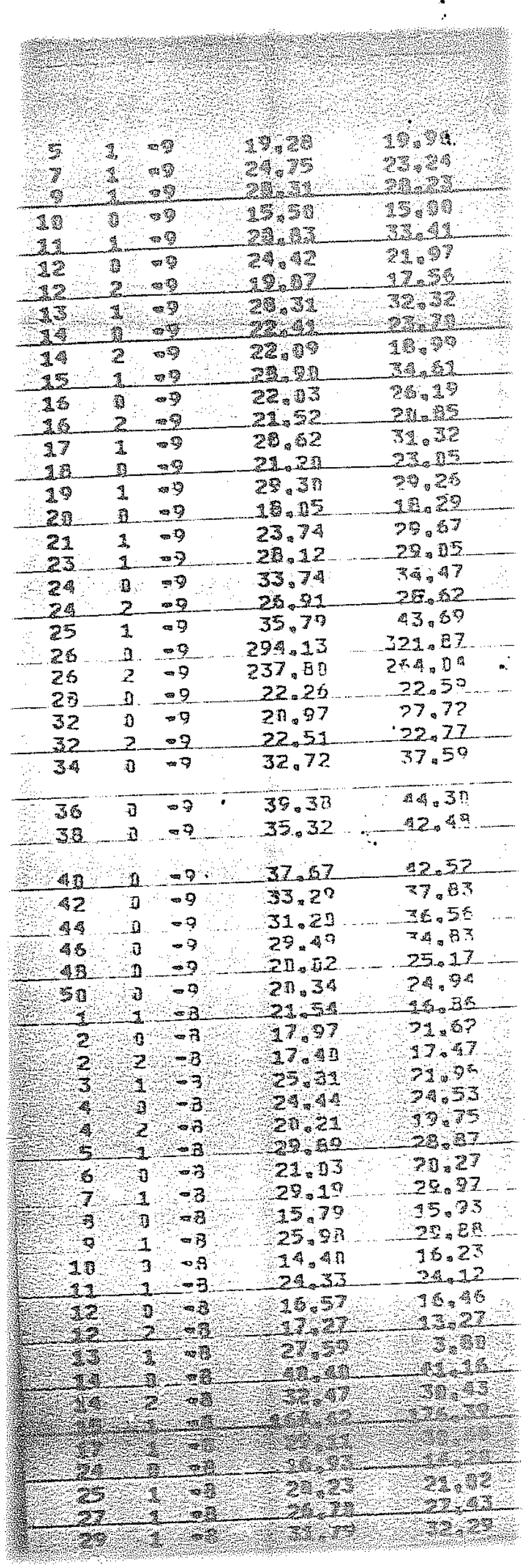




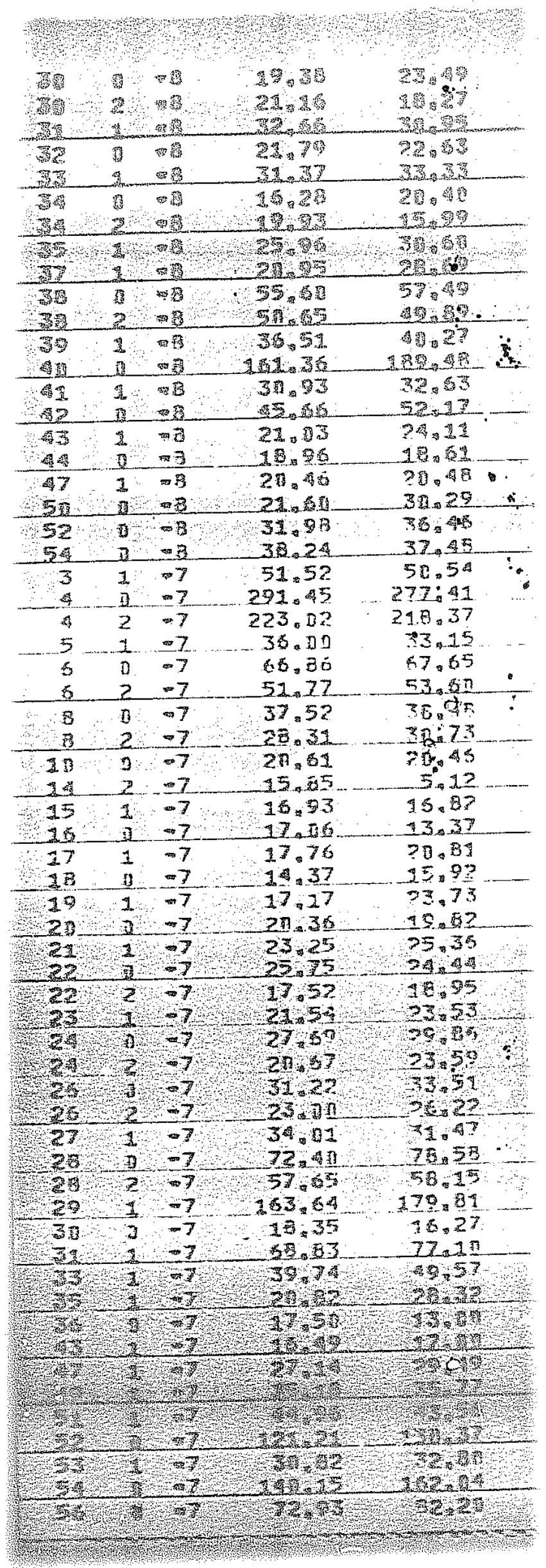




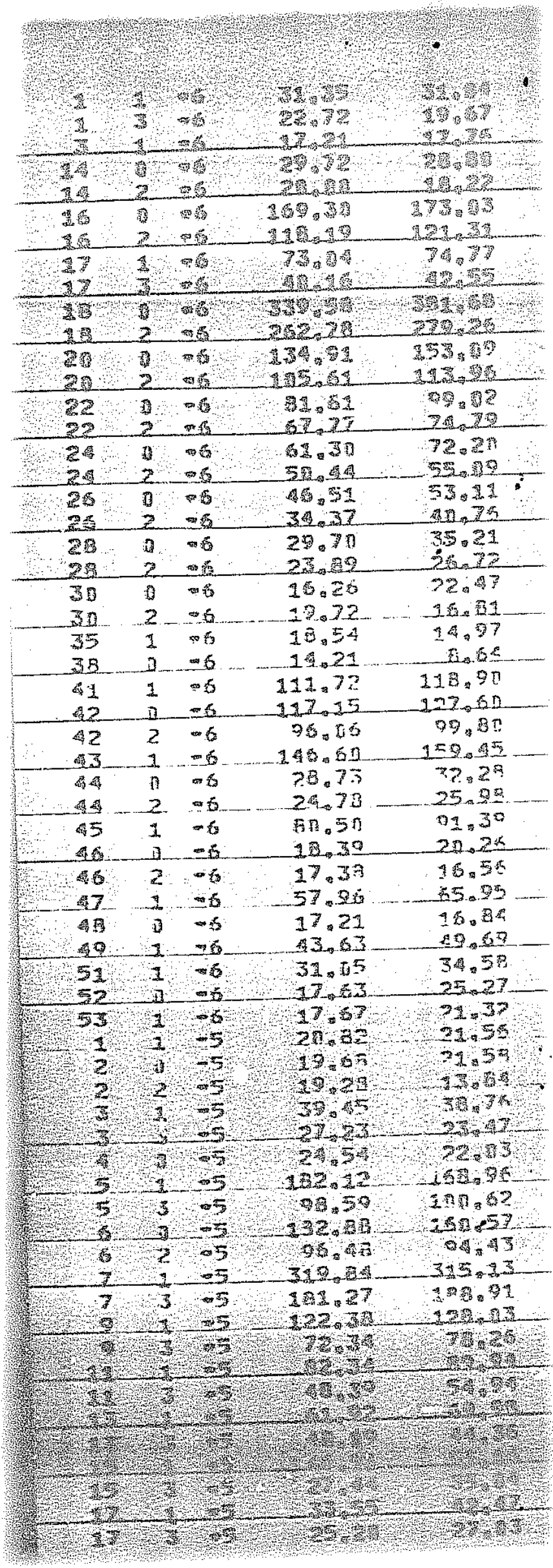




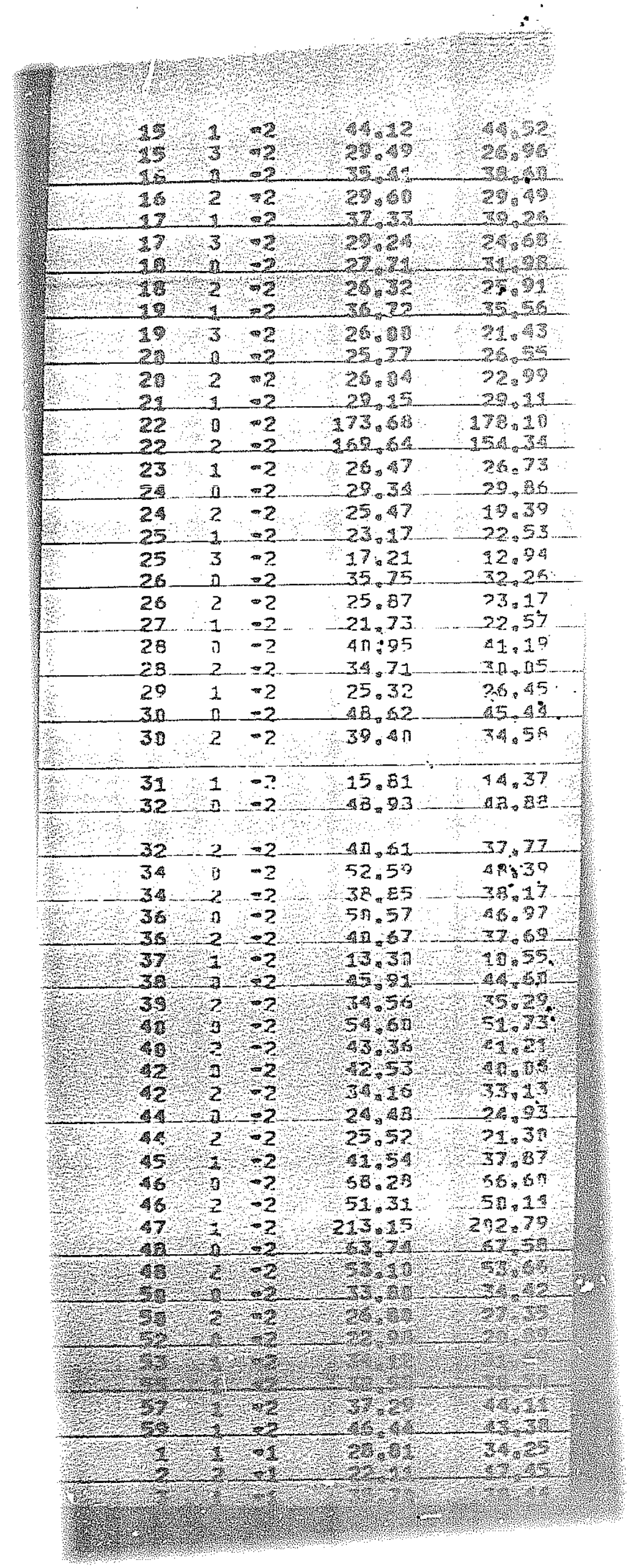




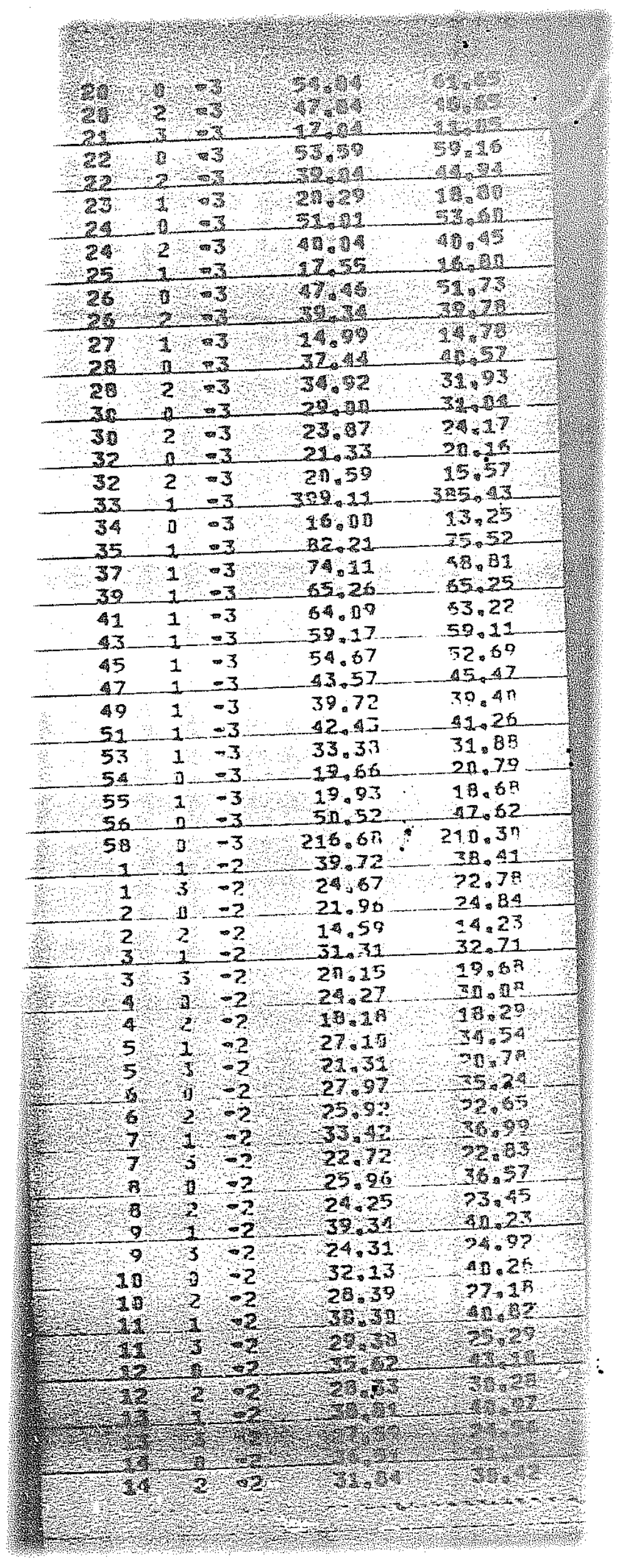




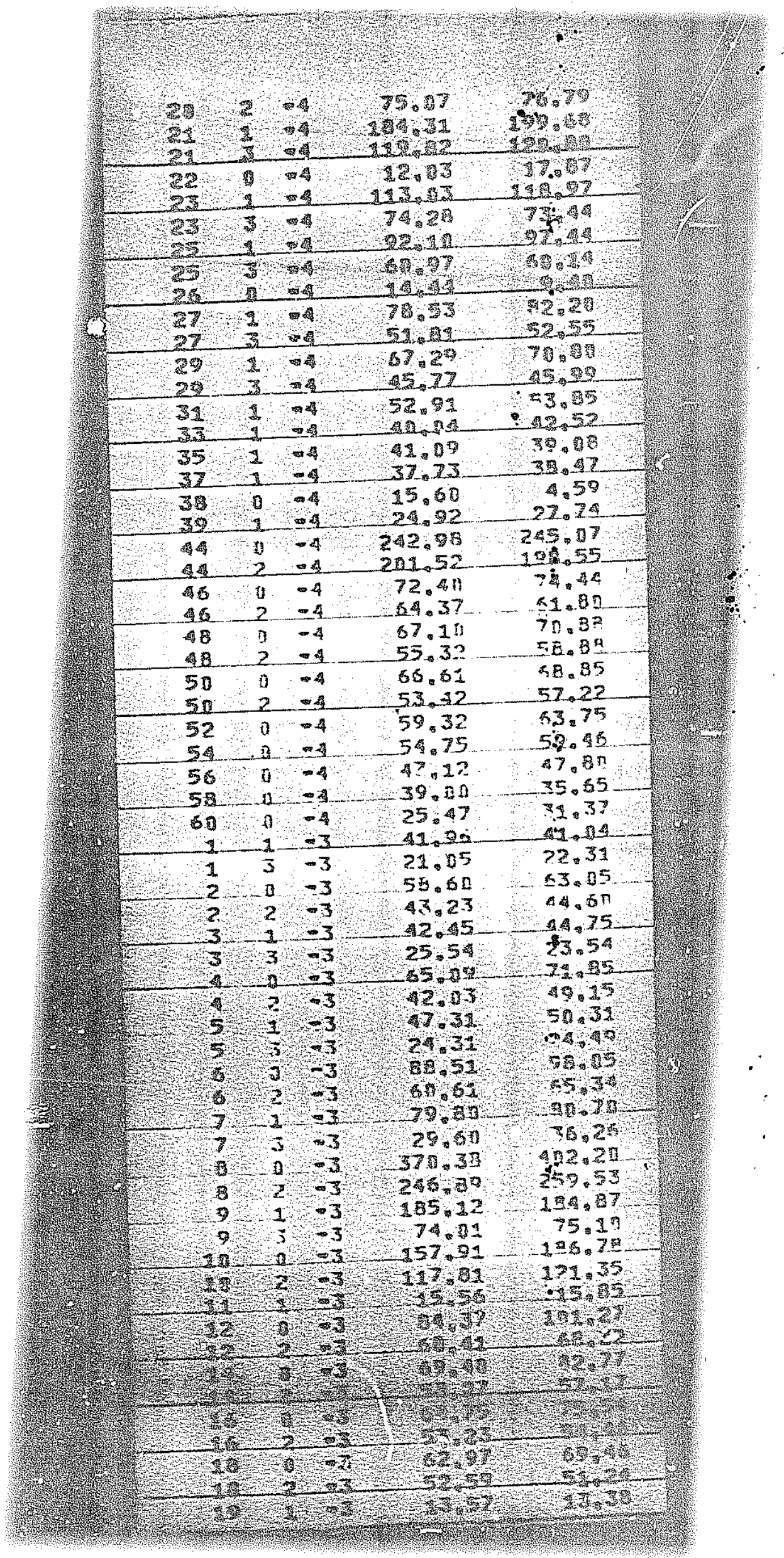




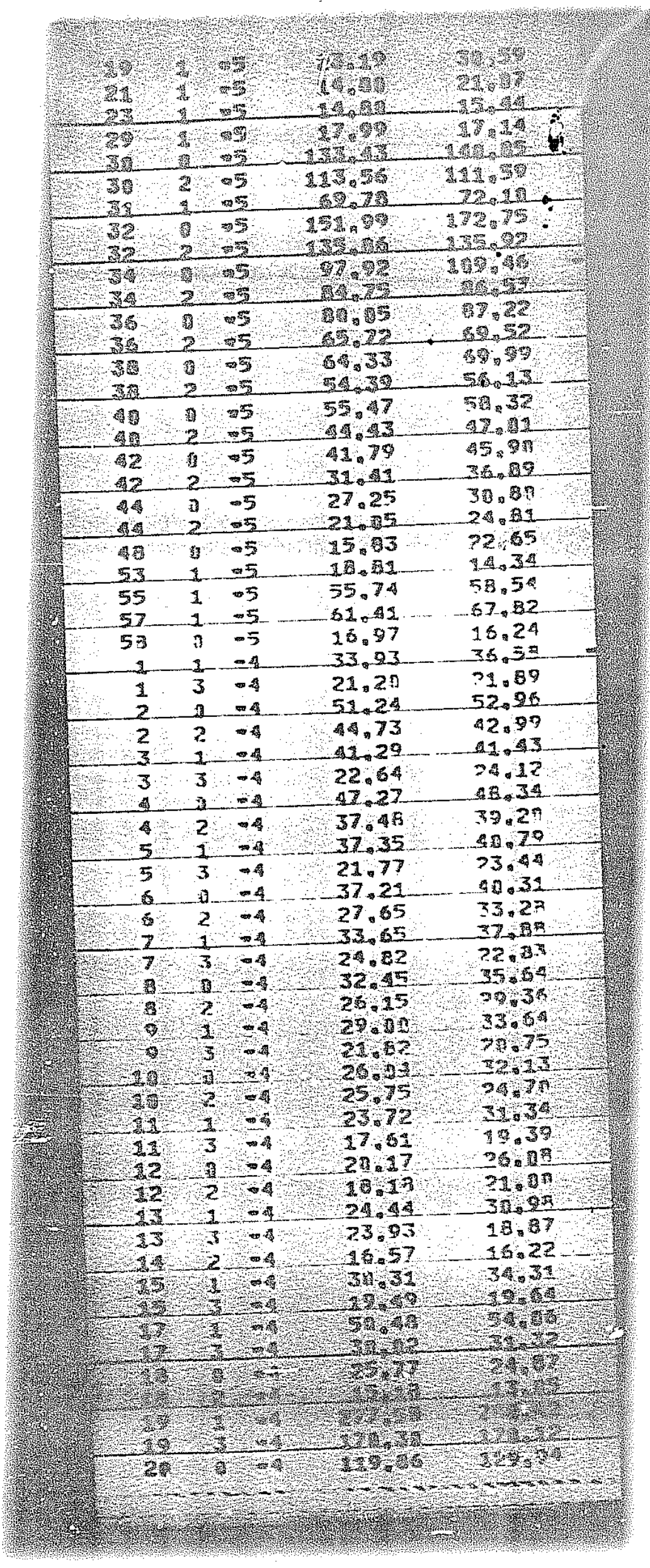




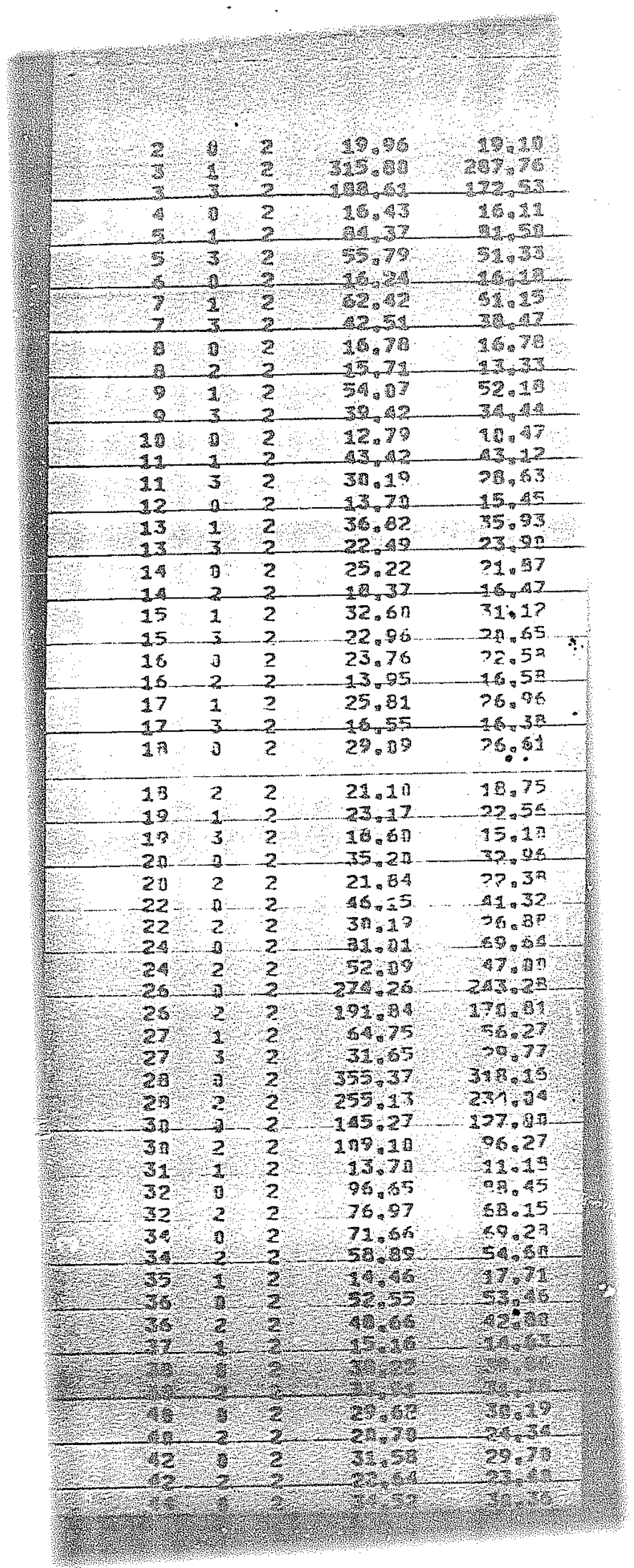




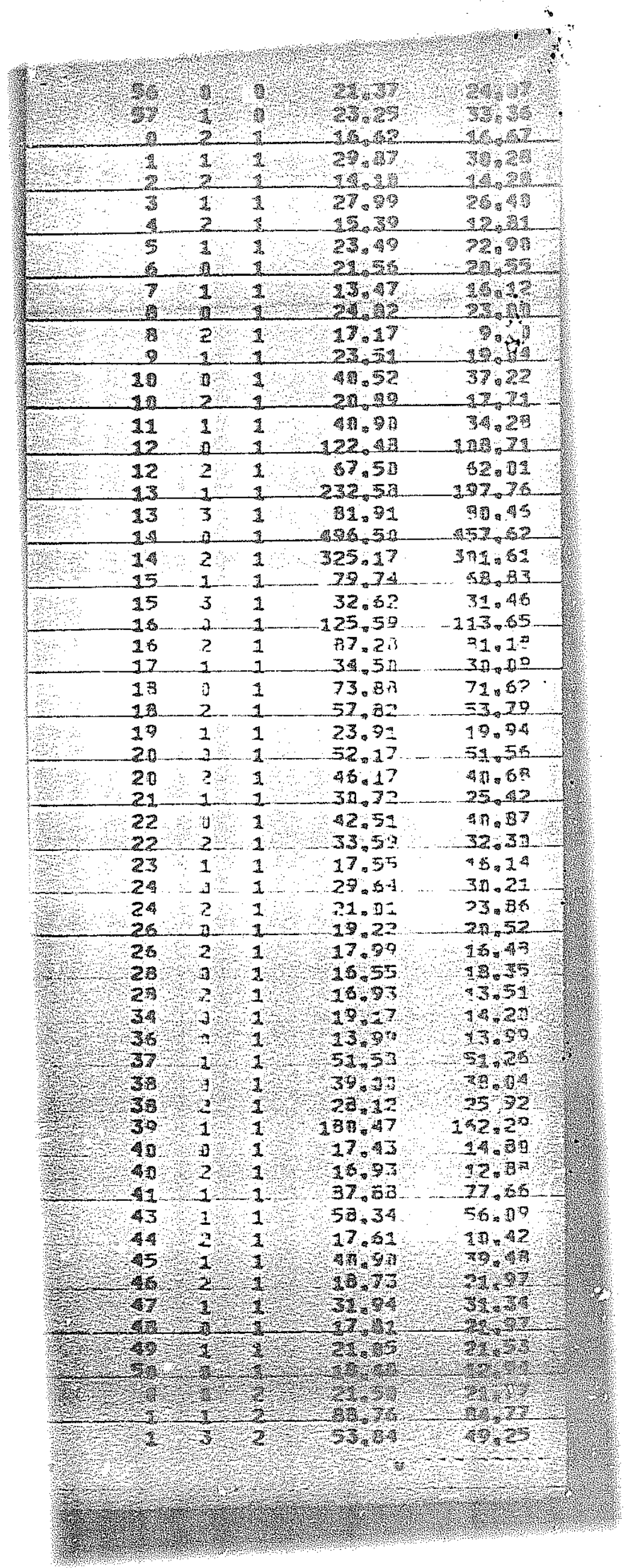




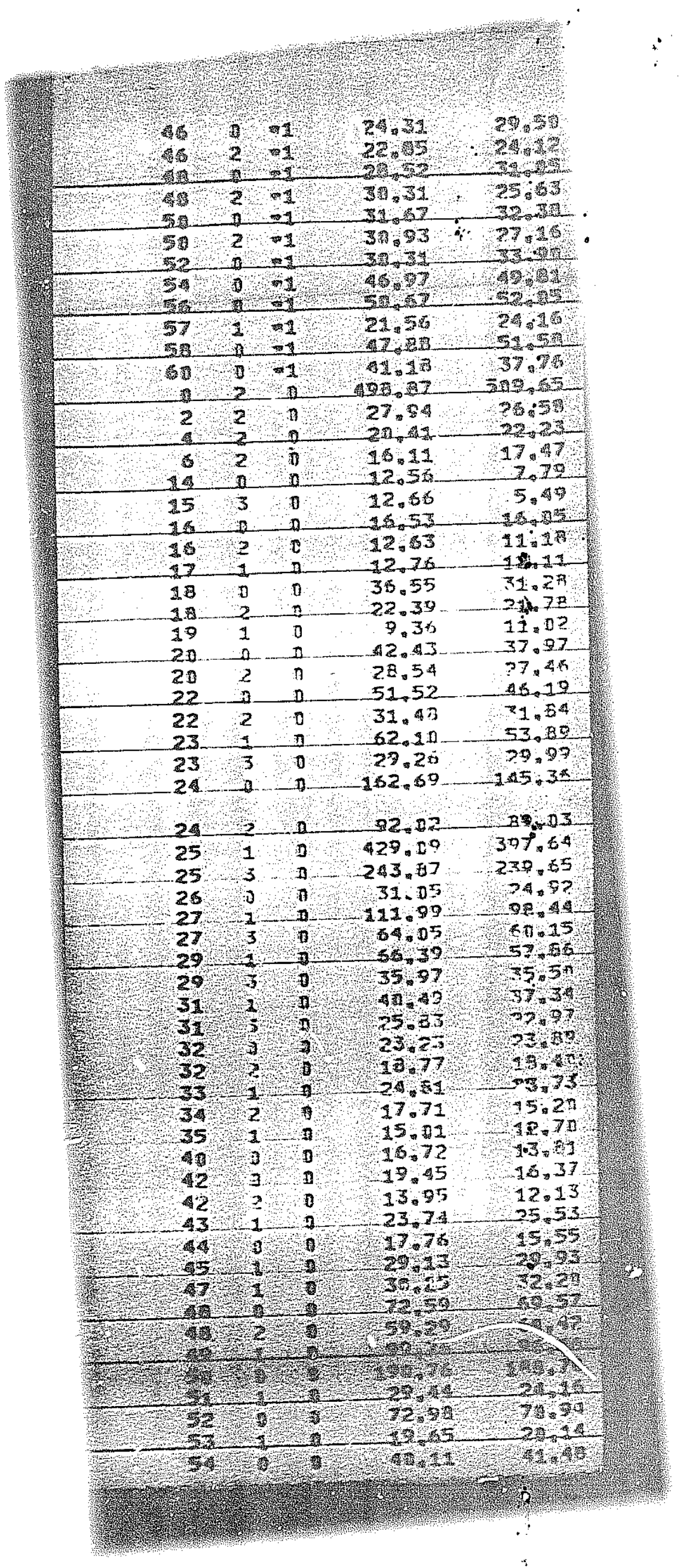




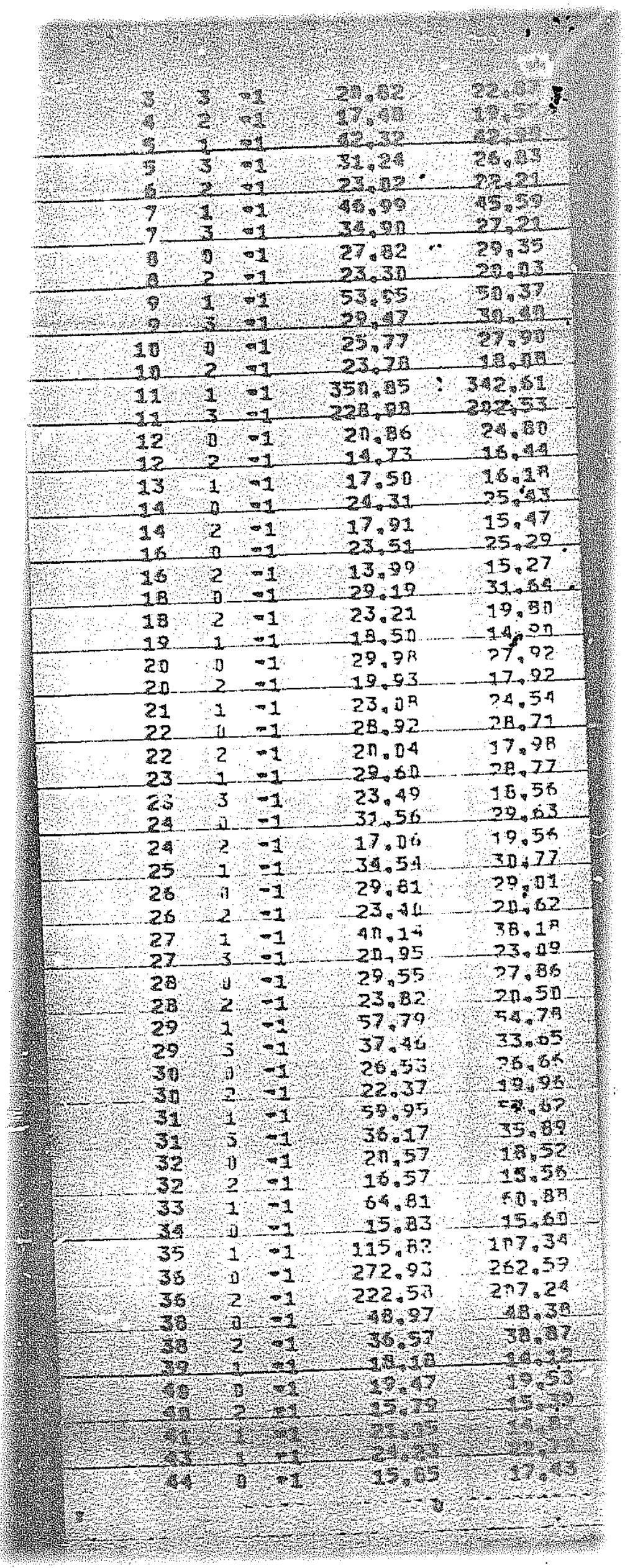




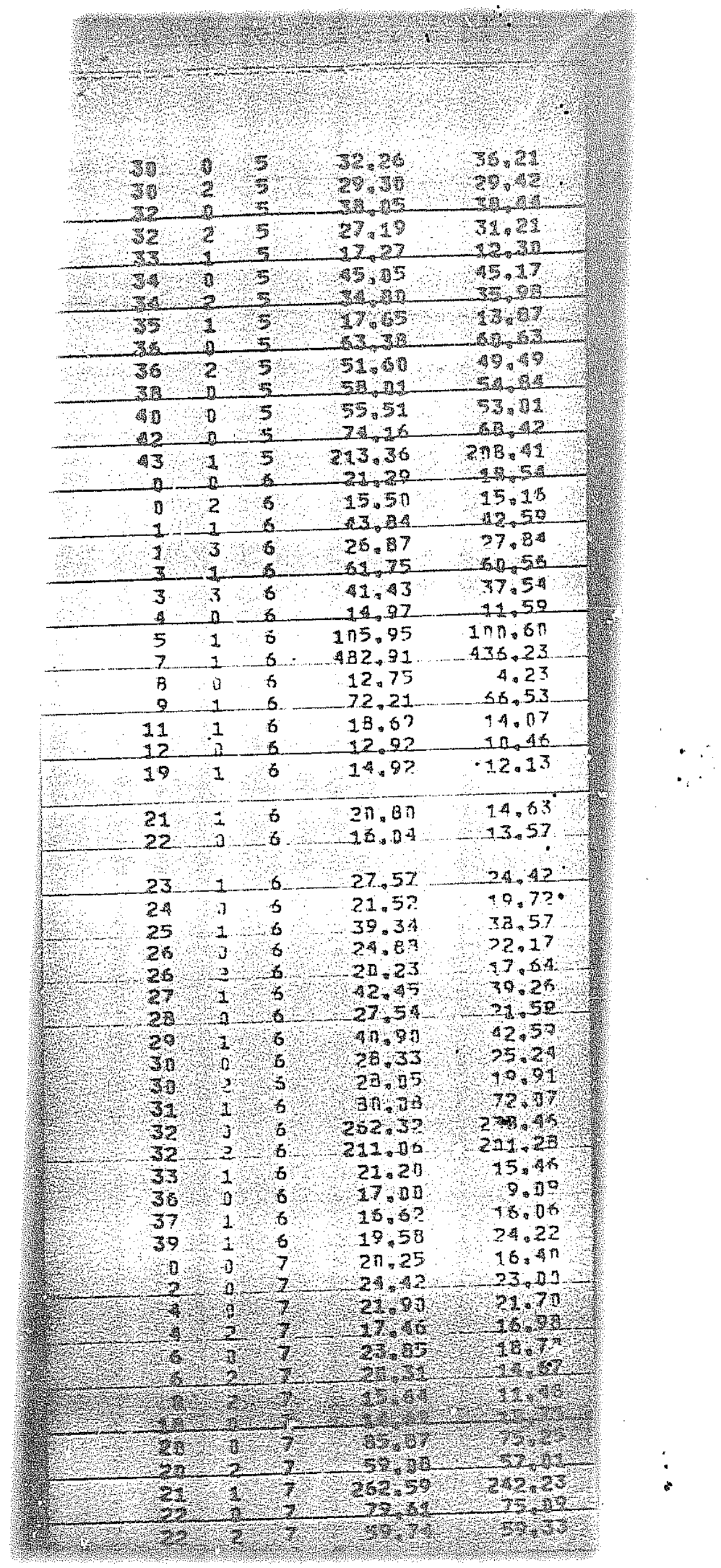




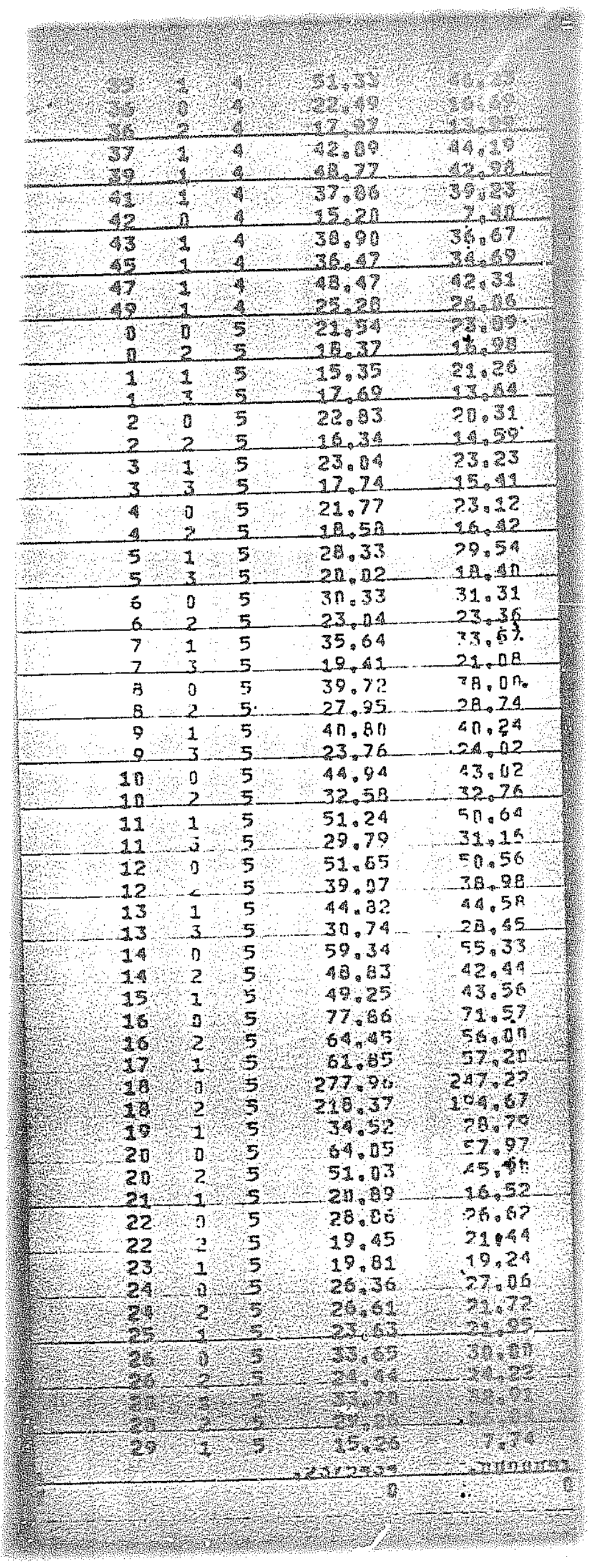




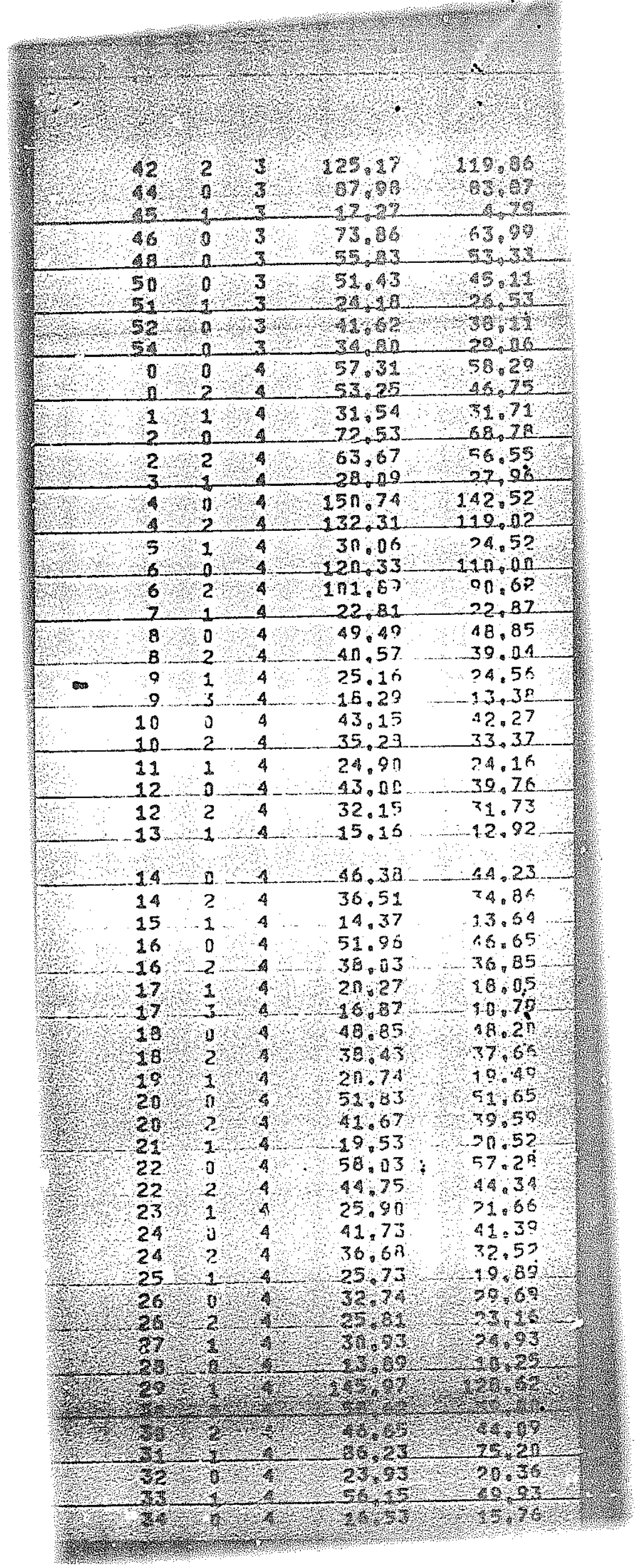




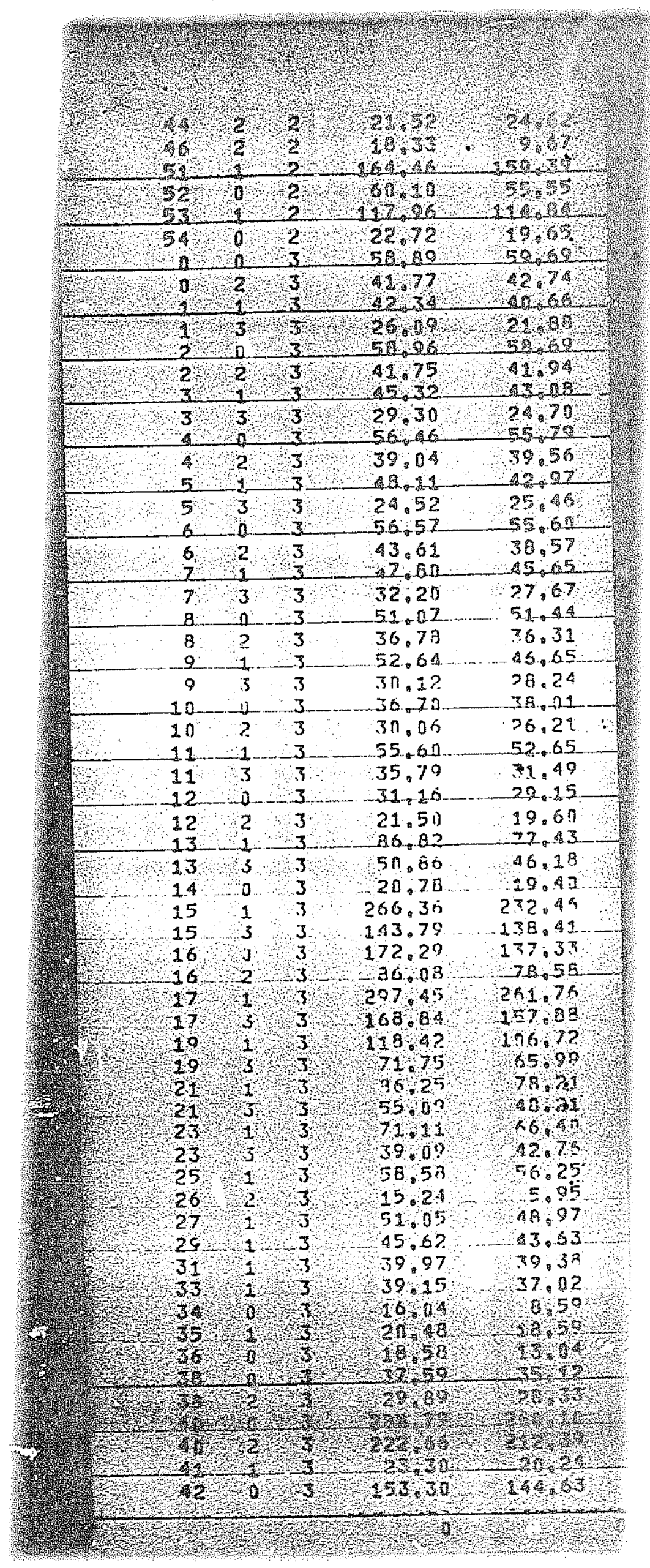




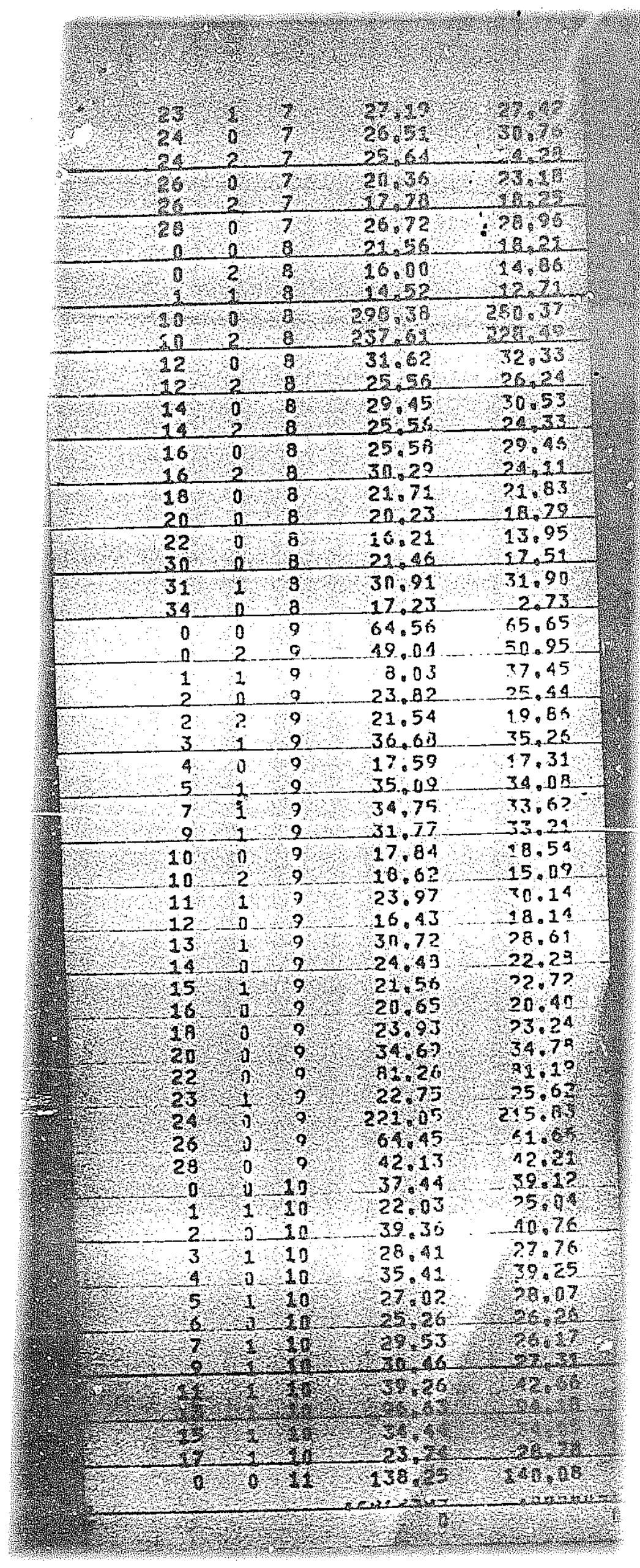




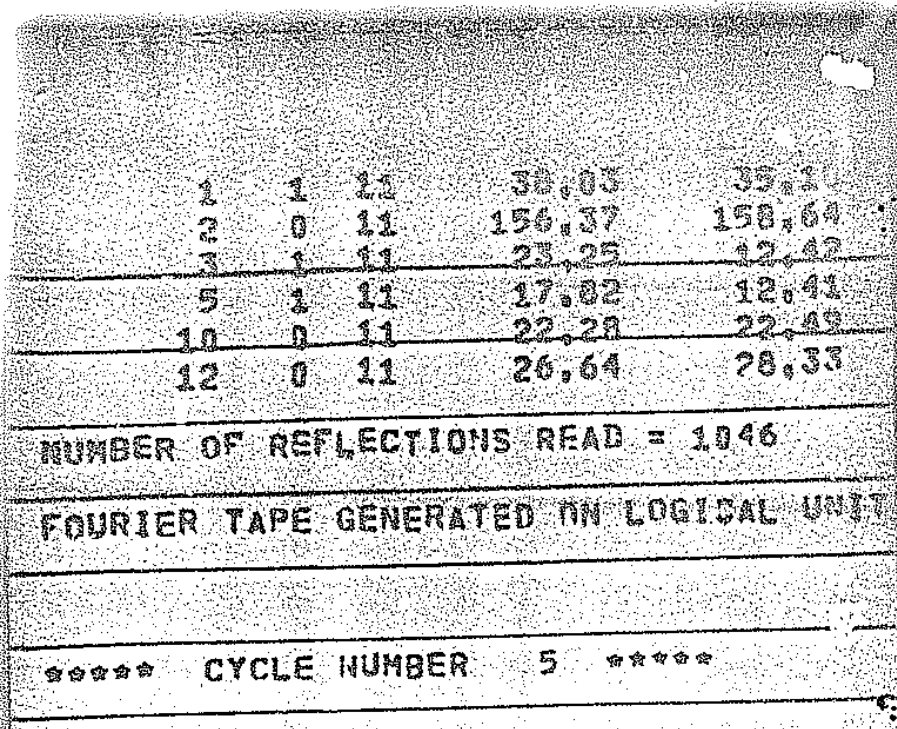

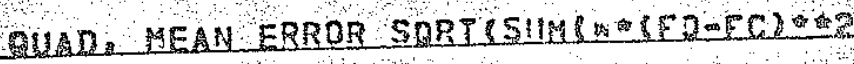

COR OBSEQVEO REELEXIONS OULY

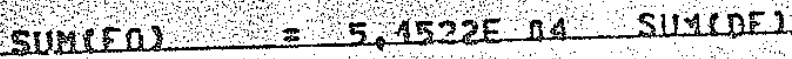

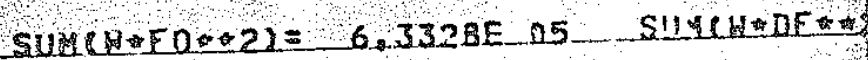

FOR ALL QEFLEXIONS

sumern)

$=5.45225, n 4 \quad 5(14(0))^{3}$

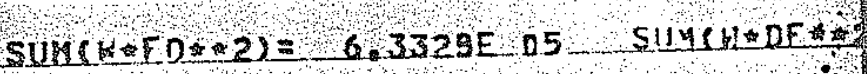

- 0 - tom- ELAPSED TIYE =

1635.720 .500

TOTAL DOR TIYE ON1 321 135 